Arab World English Journal (AWEJ) Volume 12. Number3 September 2021

Pp. $450-463$

DOI: https://dx.doi.org/10.24093/awej/vol12no3.31

\title{
A Study on Classroom Discourse in Enhancing Metacognition to Develop Writing Skill in Saudi EFL Students
}

\author{
Emtenan Agili \\ English Department, University College of Farasan, Jazan University \\ Farasan, Saudi Arabia \\ Corresponding Author: Emtenan1989@gmail.com \\ Bhagya Prabhashini C. \\ English Department, University College of Farasan, Jazan University \\ Farasan, Saudi Arabia
}

Received: 3/8/2021 Accepted: 8/20/2021 Published: 9/29/2021

\begin{abstract}
Generally, learning outcomes are not always as expected; instead, they show a degree of variation depending on various factors. Likewise, despite the fact of providing writing instruments in Saudi EFL classrooms, the outcomes are not always as expected. The reasons may range from classroom atmosphere to individual cognition and many other related variants around. However, it is a small attempt in teachers' perspective to see if anything is lacking in the implementation of 'teaching writing strategies' for EFL classrooms. To verify this assumption between practicality and literature, this paper intends to explore 'the implementation of writing strategies of faculty' during teaching writing skills. In addition, this paper also attempts to identify what sort of discourse tools and metacognitive strategies university faculty are incorporating in their teaching, and what is ignored or not used up to the mark while enhancing Saudi EFL students' meta-cognitive awareness. To collect responses for this study, a survey questionnaire was administered among 36 English language educators of the Jazan region. The results of this study revealed that there is a component that was given minor importance during teaching, though teachers used other strategies and tools extensively. Furthermore, one of the aims of the study is to demonstrate how discourse can be used to offer a solution in the present scenario. In a nutshell, this research recommends the significance of the neglected subcomponent and its importance in improving writing metacognition.

Keywords: classroom discourse, language instruction, metacognition, metacognitive strategies, Saudi EFL students, writing strategies.

Cite as: Agili, E., \& Prabhashini, C. B. (2021). A Study on Classroom Discourse in Enhancing Metacognition to Develop Writing Skill in Saudi EFL Students. Arab World English Journal, 12 (3) 450 -463. DOI: https://dx.doi.org/10.24093/awej/vol12no3.31
\end{abstract}




\section{Introduction}

Discourse is comprised of conversation/speech or written communication. According to Crystal (1992), discourse is a continuous stretch of language in a spoken form and more significant than a sentence as in a sermon, a funny joke, a narrative, an argument etc., or it is a piece of text where all are part of linguistic and paralinguistic elements of teaching.

Wells (1994) quotes the work of Leontiev and Halliday in his writing, citing discourse as a tool in the activity of learning and teaching. Similarly, Leontiev (1981) says discourse tools are the pillars of an activity as they play a central role in connecting humans to objects and other people. In 1993 Halliday expressed this a different way, i.e., the semiotic process is a distinctive property of human learning in making meaning. Over time, it has evolved as writing and then into education. The students have to recall the knowledge from their 'education' to use in semiotic context, i.e., as classroom knowledge. Based on this view, classroom discourse is a tool to develop metacognitive awareness in improving writing skills. Eventually, the aim of this research is to increase English language instructors understanding of the value of using discourse in EFL classrooms, with the goal to make students writing process more appealing and engaging.

Reviewing and analyzing the discourse tools used by educators in a classroom setting and context is the prime aspect of this study. In this study, the researchers address the benefits of classroom discourse to students writing and how classroom discourse can promote metacognitive awareness. Metacognition is a thought processing action that assists learners in gaining desegregated knowledge. We are specifically interested in classroom discourse approaches that language instructors use to facilitate the writing process. Being EFL teachers in Saudi Arabia, it is essential to discover the advantages of using classroom discourse to promote metacognitive moves in support of students independent writing. Noticing many graduate students had challenges with their writing assignments caught our attention and led to this study of what strategies and methods English instructors could utilize to benefit EFL students second language writing. Precisely, to see the use of classroom discourse in increasing students' metacognitive awareness during free-writing process. Meaningful construction of sentences involves organizing discourse structure during writing (Spivey, 1990). Classroom discourse must be precise and robust. Canagarajah, 2002 proposed the deconstruction of conventions and rules that encourage novices. To make these connections, it is necessary to find the answers for the following research questions:

1. What is lagging in the process of teaching writing skills?

2. Can Monitoring be done using classroom discourse?

From these questions it can be seen how important educators discourse is in text and speech forms to developing the metacognition of students during writing processes. This research emphasizes the practice of classroom discourse and analysis in English language classrooms so that students will be more aware of their metacognitive writing strategies and use them to improve their writing tasks.

\section{Literature Review}

Word composition in discourse is not only for subject comprehension but also provides indepth knowledge of a topic. Discourse might be a verbal or written form that helps develop 
one's language and thought process. Classroom discourse on a particular topic not only familiarizes students with sentence structure patterns but also aids in effective writing. Writing in a foreign language in an academic context is a difficult skill to acquire. Thus, it is wise to accept that merely using explicit instruction strategies isn't enough in EFL classrooms. Writing is a complex process that comprises cognitive and metacognitive strategies, for example, outline planning, brainstorming, applying, organizing, drafting, reflecting, and revising (Negari, 2011). In the same way, Hadley and Reiken (1993) state that writing is best accomplished through interaction where learners can discuss and negotiate the topic. Therefore, EFL students need to be conscious of learning strategies to be able to use them in a meaningful way.

Embedded in their writing instructions, teachers need to introduce resources, strategies, models, and methods to students that allow them to acquire and foster critical discourse analysis skills to apply to their writing (Avendaño \& Fonseca, 2009). Further, using classroom discourse supports students' cognitive and metacognitive mechanisms. Classroom discourse also helps students to become more critical thinkers. Avendaño and Fonseca also state that students need to make use of discourse statements with accuracy and uncover how the cognitive components of language are useful to disempower or to empower the writing process. With these cognitive components, English language learners begin to build their understanding and awareness of the writing process. In addition, with metacognitive components, students understand how they can evaluate, control, and monitor their learning processes (Durham \& Raymond, 2016). Writing involves the ability to transfer skills and intelligence using a variety of content areas in order to become efficient. Students are more prosperous in 'given situations', where they can make choices and reflect on written assignments in a practical environment in classrooms (Hales, 2017).

Teaching writing without relying deeply on discourse analysis leaves students at a disadvantage during the writing process. It is the main structure of reference for decision-making in language teaching and learning. Constructing appropriate contexts for illustrating, interacting, and supporting students with valuable opportunities to practice language within various situations is crucial for enhancing learning environments. Language development and language acquisition occur within a classroom discourse-rich environment (Tannen, Hamilton \& Schiffrin, 2015). Nunan (1991) points out:

Teachers play an important role in shaping classroom discourse and in maximizing learning opportunities, and TT (Teacher Talk) is of crucial importance, not only for the organization of the classroom but also for the processes of $\mathrm{L}_{2}$ acquisition. It is important for the organization and management of the classroom because it is through speech that teachers either succeed or fail to implement their teaching plan. (p. 189)

While Teacher Talk has great importance in writing classrooms, student-centered classrooms have even more benefits, such as students sharing ideas without hesitation. Student-centeredness allows students to participate in classroom discourse. Students can think actively and share their opinions and philosophies based on their personal experiences. Educators are aiming to replace the strategy of "dominating boss" with "considerate organizer and coordinator". The goal is to establish classroom activities that use a variety of interactive discourse types, such as debate, roleplay, and presentations, to arouse students' enthusiasm and interests (Xin, Luzheng \& Biru, 
2011). When teaching using authentic materials of discourse patterns, students gain a significant understanding of those specific speech events as well as the sociolinguistic elements that encompass linguistic variation across various contexts. For instance, students can learn turntaking in a conversation between friends' openings and closings on answering machine messages, or other speech events that are customarily used in second language learning contexts (Demo, 2001). This kind of natural language learning helps students to recognize discourse patterns associated with the genres. Some examples of oral discourse are ecological discourse, historical discourse, Swale's (1990) Stamp collectors' discourse community, and Schiffrin's (1980) disciplinary discourse. Cooper's ecological model (1995) of discourse suggests a social context for writers. In 2006, Bizzell used the word hybridized discourse forms. Some other specific examples of discourse are an autobiography, a documentary, etc. Thus, oral discourses may range from lunchtime talk to astronomical speeches. Right away, textbooks and authentic written material are examples of written discourse. The context provides accurate, complete information to the students in the process of writing. Killingsworth and Gilbertson (1992), Olsen (1993), Orlikowski and Yates (1994) studied ESP writing in academic contexts and proved that it is fruitful in Business courses.

When it comes to oral classroom discourse, it is essential to recognize the environment where a classroom community produces knowledge through interactions, and how students can make meaning out of it. Elective environments and situations for student writing involve clear, individualized expectations and outcomes; students are more motivated given a purpose and an audience (Hales, 2017). A discourse community is a significant variable in EFL writing classrooms. It allows interactions with the text when students make connections to their social life and can use their prior knowledge to make connections with new readers and textbooks. Jean Piaget's Schema theory explains how our previous understanding, emotions, expectations, and understandings combine as mental impressions or representations, impacting what we learn. Efficient students draw on prior knowledge and experience to assist them in grasping what they know about text and are accordingly able to use that knowledge in making connections. These connections help learners to process writing using metacognitive strategy-based practices in English classes (Erkan Cer, 2019).

Discourse structure between teachers and students during teaching and learning sessions is considered a critical method of promoting language input, aside from instructional resources from textbooks. During interactions, students can gain enough confidence to modify and attempt new sentence structures. For example, they might begin experimenting with complex sentences, such as using time or reason clauses during discussions. The learners who are encouraged to participate in discussions increased their chances of understanding the meaning of new vocabulary (Lightbown \& Spada, 2013). Between instruction and the acquisition of vocabulary, the discourse approach stands out noticeably. Vocabulary isn't isolated from context during the teaching and learning process. It can be acquired only through a larger frame of discourse that allows the meaning of words to become well-defined strategic patterns (Schiffrin et. al., 2001).

Classroom discourse is a significant step towards learners' comprehension of linguistic input. In a foreign language classroom, oral discussion is a critical means of learning a language (Kumaravadivelu, 2003). Larson and Keiper (2002) note that discussion in a classroom requires students and teachers to interact at a high cognitive and affective level. Accordingly, a 
discussion assumes to be an effective teaching technique to develop students higher-order thinking strategies through negotiation of meaning and questioning interactions. They also refer to the advantages of discussion when students explain their ideas and thoughts in a classroom; it enables students to analyze, interpret, and manipulate information, rather than merely recount or recite memorized facts and details. Consequently, when students' understanding is slow during a discussion, the interested students pay attention towards information shared during peer discussion where the ideas of social awareness are presented. Furthermore, Larson and Bruce (1997) state,

"During discussion learners are not the passive recipients of lessons transmitted by a teacher. Rather, learners will be active participants in discussions involving open-ended questions, which require students to organize available information to arrive at their defensible answers." (p.4)

Overall, appropriate input and proper contexts for discourse among students leads to successful second language acquisition (Luan \& Sappathy, 2011). This acquisition corresponds to Vygotsky's theory of second language acquisition. Vygotsky's acquisition states that the learners acquire language when they interact verbally during language learning process (Lightbown \& Spada, 2013). Moreover, Larson and Keiper (2002) explain the advantages of verbal interaction in a classroom by uniting the cognitive and "social aspects" of a school. Furthermore, learners can receive immediate feedback during discussions. For further advantages of discourse in a classroom, the comprehensible input hypothesis developed by Krashen states that learners acquire language in only one way. This acquisition is by understanding messages or receiving comprehensible language (Lightbown \& Spada, 2013). Based on this theory, Luan and Sappathy (2011) summarize the need of understandable input before learners can internalize it through negotiation and investigating its forms and features. They explain that acquisition happens when learners obtain intelligible input.

The scores are more in integrated writing tasks rather than independent writing tasks, for example, Listening and Writing tasks in TOEFL. According to Engber (1995), Ishikawa (1995), Jarvis et al. (2003), Machon et al. (2000), Ortega (2003) and Sasaki (2000) there is some research with independent writing tasks about the features and process of discourse in writing proficiency. Writing using a speech, extensively by reading a piece of text or listening to a sermon is an integrated writing task. In a way, the students come across the discourse vocabulary to use within a writing task. Hence, this is an attempt to see what is lacking in teaching 'writing' and how to overcome it.

The purpose of this study was to discover whether educators are using discourse analysis tools to develop their students writing. To carry out a writing task, it is a prime need to define a list of specific metacognitive components. The definition for metacognition in Critical Transitions given by the National Research Council (2000) is the ability to monitor the level of comprehension and estimate if it is more than sufficient. Scott and Levy (2013) proposed five metacognitive components: Knowledge, Planning, Monitoring, Regulation, Control, and Evaluation. Knowledge includes subcomponents such as Person, Task, and Strategy, whereas Planning includes with the other three components. Harris, et al. (2009) explained the component Person by expanding on the idea that success and non-success of the student depend on what elements they are 
comfortable with doing in the task. O' Malley (1990) suggested three main metacognitive strategies: Planning, Monitoring and Evaluation. Gorzelsky, Driscoll, Pazcek, Hayes and Jones et al. (2016) proposed a taxonomy for metacognitive sub-components. When these metacognitive subcomponents are used in teaching, they help students with metacognitive moves to complete their writing tasks. They added a new sub-component, Constructive Metacognition and considered each component of Scott's Knowledge as an individual subcomponent. They are Person, Task, Strategy, Planning, Monitoring, Control, Evaluation, and Constructive Metacognition. Lastly, a basic component of sentence formation in writing is the need for grammar knowledge. When students understand the rules of sentence construction and put them into action to frame sentences, they take the next step to an improved writing process. To improve, students need prior knowledge of the topic to form an increasing number of sentences without losing consistency. Consequently, here students will apply their knowledge about grammar and prior knowledge about topics to further develop their writing. They need skills to be able to transform that knowledge in order to write about a topic in different scenarios. While doing this, the use of metacognitive sub-components, such as genre knowledge, is necessary. Moreover, comments from friends and family benefit the student by reinforcing the impressions of writing style from practice. Taczak and Robertson (2016) quoted, practicing what all reflected or revised as an after-the-fact activity is necessary during the process of writing.

\section{Method}

The list of subcomponents provided by Gorzelsky, et al. (2016), were the most applicable in terms of function in writing classrooms (Table one). For each of these metacognitive subcomponents, specific metacognitive strategies and discourse tools that apply to writing skills help educators assess if they are following these subcomponents to get consequent metacognitive moves. Discourse tools are one of the teaching tools for educators and the discourse strategies relate to each metacognitive subcomponent. Wells (1994) called them discourse categories and discourse tools. There is a strong correlation among them, all important to the facilitation and implementation of the strategies in EFL classrooms. Also, the strategies make connections between metacognitive elements and discourse tools; classroom discourse shows the teaching method of EFL writing classrooms.

Table 1. Metacognitive subcomponents, specific metacognitive strategies, and classroom discourse tools (based on Gorzelsky, et al., 2016, p. 226)

\begin{tabular}{|c|c|c|c|}
\hline $\begin{array}{l}\text { Sl. } \\
\text { No }\end{array}$ & $\begin{array}{l}\text { Metacognitive } \\
\text { Sub-compo- } \\
\text { nents }\end{array}$ & Specific Metacognitive Strategies & Classroom Discourse Tools \\
\hline \multirow[t]{3}{*}{1.} & \multirow[t]{3}{*}{ Planning } & Identification & sample text \\
\hline & & Brainstorming, Outlining and Composing & $\begin{array}{l}\text { conversations, classroom discussions, concept } \\
\text { maps, rearranging texts elements }\end{array}$ \\
\hline & & Organizing and applying strategies & students collection of text data, vocab exchange \\
\hline \multirow[t]{3}{*}{2.} & \multirow[t]{3}{*}{ Monitoring } & Pre-writing & cutting up texts into discourse structures \\
\hline & & Drafting & peer talk \\
\hline & & Monitoring & Pedagogue discourse \\
\hline \multirow[t]{3}{*}{3.} & \multirow[t]{3}{*}{ Controlling } & Edit & using checklists \\
\hline & & Comparison & exchange of work \\
\hline & & Revision & written cards of clues/rules \\
\hline
\end{tabular}


Arab World English Journal (AWEJ) Volume 12. Number 3. September 2021

A Study on Classroom Discourse in Enhancing Metacognition

Agili, \& Prabhashini

\begin{tabular}{|c|c|c|c|}
\hline \multirow[t]{3}{*}{4.} & \multirow{3}{*}{$\begin{array}{l}\text { Evaluation of } \\
\text { quality }\end{array}$} & Feedback & suggestions from peer and pedagogue \\
\hline & & Assessment & self-analysis \\
\hline & & Evaluate & analyzing strengths and weaknesses \\
\hline \multirow[t]{3}{*}{5.} & \multirow{3}{*}{$\begin{array}{l}\text { Constructive } \\
\text { metacognition }\end{array}$} & Reflection step-1 & explanation of theoretical concepts \\
\hline & & Reflection step-2 & offering the choices of evaluation \\
\hline & & Reflection step-3 & provide confidence of writer's identity \\
\hline
\end{tabular}

As stated previously, the main focus of this study is on writing skills as an essential skill for the future endeavors of students, such as career advancement or documentation skills. As Nowacek (2011) emphasized, meta-cognitive support is critical to the development and transfer of knowledge related to writing skills. Hence, this study looks for the frequency of the aforetabulated strategies usage by the faculty teaching graduate students.

\section{Participants}

This research aimed to collect relevant data from university faculty teaching writing courses of English at university level. Forty teaching staff participated in the current study. All the staff teach graduate-level courses to students who are studying English as their major. As we reside in a sparsely populated area, the Farasan Islands, to reach the targeted number of responses, colleagues who teach graduate courses at several colleges within the university were approached. All the administered faculty have mastered their content areas and have teaching experience of more than three years.

\section{Research Instruments}

A questionnaire was the primary research instrument of this study, used to self-check what metacognitive subcomponents teachers use or don't use in their writing classrooms. Further, it was chosen as a method to discover what specific metacognitive strategies and discourse tools teachers employ to aid students in their writing. The faculty questionnaire consisted of 15 question items based on specific metacognitive strategies and discourse tools used in writing classrooms. It contained questions concerning various strategy elements and the correlated discourse tools they currently use. Responses were collected using a three-point Likert scale. The questions were framed in the same form and sequence. All the questions were designed with a goal of discovering whether teachers are using classroom discourse tools to develop their student's writing skills. Further, the questionnaire was used to see how far they agree that the metacognitive subcomponents match the metacognitive strategies mentioned in Table one. As four responses were incomplete, 36 responses became the data for analysis. The responses were then configured as bar-graphed histograms (Figure two) to show how often teachers are using the discourse as mentioned above, and tools to develop meta-cognitive awareness among their students, with the goal of improving writing skills.

The study of specific metacognitive strategies helps to expand students' knowledge of writing through composing and drafting using classroom discourse tools mentioned above. Together, these lead students towards maturity in their writing. For example, strategies might include consistency of thematic progression to be maintained using rearrangement of the sentences of a topic, while discussion and conversation improve their confidence level. This confidence build-up gain aided by a comprehensive plan of how to structure issues. Further, Bransford, D., Brown, A., and Cocking, R. (2000) stated that metacognition helps learners to comprehend and guide them in the same way in new situations. 


\section{Result Analysis}

Before the data analysis, we will briefly discuss how classroom discourse is emphasized over other types of speech. Discourse is formal and debates, whereas Speaking is an exclusive ability. For e.g., a speech at a graduation ceremony. Discourse is usually a lengthy exposition and involves exclusive focus on the subject. Further, it allows communication through conversations. Regular speech in the classroom is different from discourse because it engages students and builds up self-regulatory mechanisms in students. Through this, organizing and strengthening thought processes of students takes place. This thought processing permits them to understand the importance of the role of consistency in writing a free article. Coming to the data as outlined above, we analyzed the following results.

This data analysis focuses on five metacognitive subcomponents and specific metacognitive strategies used in writing tasks, and the particular discourse tools that correlate and aid in writing classroom teaching. Approximately $72 \%$ (see Figure one) of the faculty agreed that they were using discourse tools with students to help in their writing. Twenty and fifty-five hundredths agreed 'to some extent', that they were following metacognitive elements in teaching writing to transfer the knowledge. Seven and two tenths of the faculty said that they weren't implementing any metacognitive strategies in their teaching.

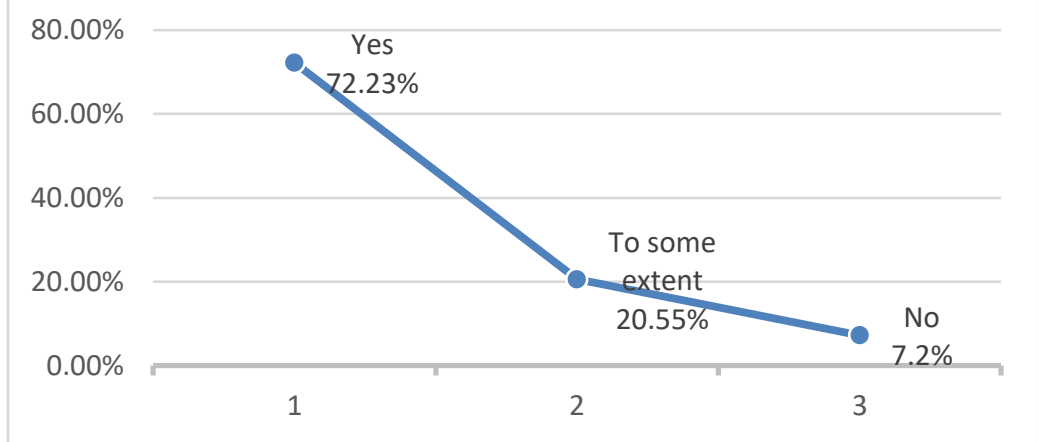

Figure 1. Questionnaire results: Overall response of using metacognitive strategies and classroom discourse tools

Gorzelsky's five metacognitive subcomponents mentioned in Table one are: Planning, Monitoring, Controlling, Evaluation of Quality, and Constructive metacognition. These subcomponents deal with metacognition in the process of teaching writing. The use of these subcomponents by the faculty has resulted as follows:

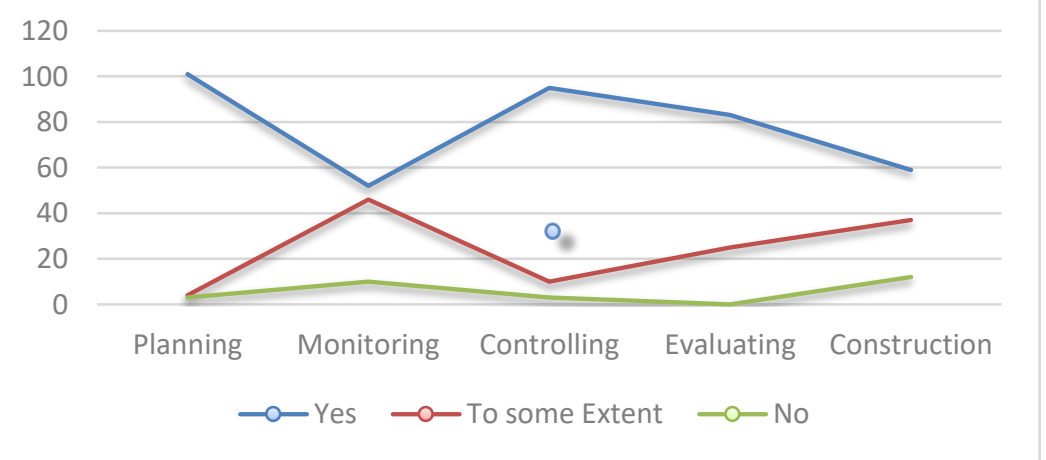

Figure 2. Questionnaire results: use of metacognitive subcomponents 
Figure two displays that the faculty Planning about teaching writing is $93 \%$ and the second one is Controlling which stands at $88 \%$. The percentage for the third subcomponent, Evaluating resulted around $77 \%$, and the next subcomponent, Construction stood at around $55 \%$. The most minor important subcomponent is Monitoring, which stood at $48 \%$. This result needs to be pondered.

\section{Discussion}

Initially, analyzing of Planning is the first metacognitive subcomponent in the study. In this category, teachers reported that they were using the discourse tool 'rearranging text elements' with students to help students to increase their 'composing' ability for coherence. The data showed all the faculty were using classroom discourse tools such as context-based discussions and conversations as part of the Planning subcomponent. Arguments, cases of a task, and activating previous knowledge typically make students want to volunteer and express interest in a new topic. Secondly, most of the teachers used sample texts as a conversational aid to guide students in recognizing the topic. Conversations and discussions brought new ideas to students and were used to create topic outlines and concept maps. The extra output from students was an uninterrupted writing flow. Vocabulary exchanges during short talks, or using discourse markers such as sounds great, good deal, however, etc., to 'generic name', 'functional role' etc. were applied using the strategies that provided an inventive use of new vocabulary. Students collected text data to assist in organizing. In other words, the data allowed them to read and make arrangements or preparations ahead of writing tasks. Students' collecting and rearranging texts assisted in composing and organizing sentences. As $93.51 \%$ opted for 'agree' and $3.7 \%$ opted for 'to some extent' options, it demonstrates that around $97 \%$ of teachers implement the Planning subcomponent. This demonstrates that most of the faculty are using metacognitive subcomponent Planning in their classrooms.

The second metacognitive subcomponent, Monitoring, encourages peer talk so that students can engage in a task. By allowing them to talk with their peers, they can share ideas, complications, and clear up uncertainties. It also includes rearranging the texts for composing with a constituency as a way to retain fluidity in writing. The data shows $48 \%$ of the faculty are using the subcomponent Monitoring in the classrooms. Another 43\% are using to some extent whereas $9 \%$ aren't using monitoring strategies or classroom discourse tools. Since only $50 \%$ of the faculty reported using this subcomponent to some extent, monitoring students while they are practicing writing skills is an area that requires additional focus. Monitoring allows students to benefit from metacognitive moves during writing.

The third metacognitive subcomponent, Controlling, includes checklists to verify if the students incorporated what all they needed to when completing a task, such as adverbs of time, adjectives, clauses, etc. In this way, students begin editing what they have written. In this subcomponent, opportunities to compare their work with others are encouraged. Also, written cards of clues or rules help with revision by cueing previously learned practices and topics easily as they are handy. During examinations, they aid students with comprehension as they can revise using their written cards. In this way, the results show that $88 \%$ of the faculty are using the Controlling subcomponent, and $9.3 \%$ are using it to some extent. Only $2.7 \%$ reported that they are not using this metacognitive subcomponent. 
The fourth is the Evaluation subcomponent, comprised of assessment, feedback, and evaluation. Self-analysis, peer and pedagogue suggestions, and understanding of their weaknesses and strengths of writing provide students clarity about the point where they need to strengthen their writing abilities. Seventy-seven percent of teachers opted 'agree', and 23\% opted 'to some extent' options about using Evaluation subcomponent in their writing classrooms. Overall, the faculty are implementing the Evaluation subcomponent while teaching writing.

The data in the final category, Constructive Metacognition, shows $54.6 \%$ of the faculty are regularly using this subcomponent, whereas $34 \%$ are using it to some extent. Eleven and onetenths reported that they are not using this metacognition subcomponent. Constructive Metacognition is another area where the faculty need additional focus, as it is essential to build confidence in students to turn them into competent writers. Students will benefit from the skills created by this Constructive Metacognition subcomponent. Self-analysis and a pedagogue's evaluation of pupils' drafts help them make a final draft that overcomes the weaknesses of their earlier drafts. Feedback from friends, teachers, and others helps them in strengthening the concepts and to use them in their writing.

The results of our survey show a strong association between specific metacognitive strategies and the classroom discourse tools used by the participants of the study. Moreover, there is identifiable week association in Monitoring and Constructive metacognition subcategories. Finally, there is a positive association between the tool and the strategy used to enhance metacognition. This association proves that the faculty are successfully using discourse analysis approaches help students to raise their writing proficiency. Still, it is very typical for EFL students to struggle. This challenge indicating the students' writing needs improvement because of the lack of progress during Monitoring and Constructive Metacognition. The tools chosen here are a great support for students and teachers to help and sustain meta-cognitive abilities during writing tasks.

In accordance with the results, specific metacognitive strategies address students' writing challenges. It is identified that two metacognitive subcomponents, Monitoring and Constructive Metacognition are used by approximately $50 \%$ of teachers. This percentage demonstrates a need for attention as they are not in practice as much as other discourse tools. These two metacognitive subcomponents need to be given more importance in writing classrooms to develop reflection strategies. To overcome this deficiency, the curriculum should provide more time, and increased support for teachers for Monitoring and Metacognitive Construction in writing classes. These two subcomponents assist in building up students' writing skills because classroom discourse allows students to get the benefit of enjoying and exploring effortless and flexible writing. During writing, the faculty use discourse tools related to various specific metacognitive subcomponents. There are many resources of discourse tools executed in interactive ways where the students discuss mindfully and begin exploring ideas to use them in writing sentences.

Writing is a way of expression using script and spelling as words. Writing and Speaking are productive expressions. Both are the same, but at the same time, writing is formal as the words are not precisely similar to the words we speak. Even speech has differences, with features such as timbre, pitch, tone, etc. Discourse in a strategic way helps students acquire pocket guides of vocabulary. The learners use this vocabulary unconsciously during writing with metacognitive 
moves. The students' ability to use content-related vocabulary is strengthened through discussions of situated cognition during or after discourse. Feedback is the process where the students are aware of errors, which needs consciousness (Bakhtin, 1986). Per Canagarajah's (2004) statement, voice is a manifestation of discourse in the form of language. It is not just a voice, but the inner 'self' of the students' unsustainability of ideology. Elbow (2007) stated,"about voice/self, multiple and dynamic discourses do not create theoretical problems that make the figure of voice unsustainable but rather create psychological problems for the writer to resolve".

Here, it is to remember again that reading textbooks are purely academic discourse. Metadiscourse is a discourse about discourse, and it is a characteristic feature of communication in many settings. Students reading books is not enough for them to be able to use rhetoric and metaphoric construction of sentences as they can't apply that reading as academicians. Therefore, as part of regular classes, faculty should monitor EFL students' writing process to improve metacognitive moves in conventionally coherent ways. The schematic structure of the discourse reveals connections of related ideas, both within and outside the text. Students benefit from discourse analysis in metacognitive awareness that aids them in featuring the texts and communications. Thus, they are aware of the discourse strategies for connecting purposes.

skills because Person is independent/student. Task is level-dependent, and Strategy is knowledge of cognition, and again, it is dependent on subject. Wardle (2007) notes, as quoted by Gorzelsky, et al. (2016) in their constructive metacognition, the development of metacognitive skills among students is of much importance because it can cultivate language, meta-awareness in writing, and rhetoric strategies. Therefore, considering the level of English, students' choices should also be given priority while choosing topics. Further limitations are the fact that this study is small because the responses are 36. In addition, the responses to the questionnaire are collected only from the teachers' point of view. There is no correlation given with grades/progress of the students, and there is no practical use of strategies to measure results. These areas are all worthy of further study.

\section{Conclusion}

The primary purpose of this study is to provide teachers with information to commission their discourse tools to include all metacognitive elements adequately to fulfill all the strategies. So, as shown by the faculty survey, two metacognitive sub-elements need to be given more attention in writing classrooms. Monitoring of students' writing can be emphasized and implemented by observation and exchanging specific vocab within the groups since this leads student to streamline their writing. Also, this assists those who think or write outside the box. Again, it also helps to avoid inconsistency. Consequently, it leads to constructive writing through reflections and choices offered to them, and the self-assurance built during discourse. It is to recommend to motivate students to become interested in English writing with exciting topics and by creating awareness about the importance of writing.

Students build their current writing skills based on the verbatim of pedagogue discourse. Hence, it will be a solution to develop metacognitive moves to continue writing. Pedagogue discourse can be a textbook or can be an oral discourse on a particular topic. About the current deficiency of Gorzelsky's Monitoring in faculty teaching of writing, oral discourse helps in increasing students' metacognition in writing. As the goals of the classroom community are 
Agili, \& Prabhashini

identical and the faculty have to focus on discourses to complete the writing tasks in a hybrid way by using both oral and written discourses. Whether a student is an insider or outsider of a discourse community, they should profit from meaningful collection with verbalizing parallels. Consequently, students improve writing worthy sentences without knowing that they are using rhetorical moves as discourse works in classroom community.

\section{About the Authors:}

Emtenan Agily has recently joined the faculty at Jazan University, KSA. She has an interest in the field of linguistics and teaching English as a second language. She completed her Masters in Teaching English to Speakers of Other Languages (MA-TESOL) at Gonzaga University in the United States. As she gained valuable experience teaching different levels during courses at Gonzaga University, it allows her to practice the theories and techniques that she learned during the course of study. https://orcid.org/0000-0003-2734-7517

Dr. Bhagya Prabhashini $\mathbf{C}$ is working for Jazan University as an English faculty at Farasan University College, KSA. She had her Ph.D. credentials in English in the field of Applied Linguistics. She previously had 18 years of experience in teaching English in India, Eretria, and Saudi Arabia. Her research areas of interest are Research Methodology, Eco-linguistics, Stylistics, Psycholinguistics, Neurolinguistics and Sociolinguistics.

https://orcid.org/0000-0002-8311-3857

\section{References}

Avendaño, C. E. M. \& Fonseca, M. H. (2009). Use of discourse analysis to enhance students' critical thinking skills. Zona Próxima, 10, 36-49.

Bransford, D., Brown, A., \& Cocking, R. (2000). How people learn:Brain, mind, experience and school. Committee onDevelopments in the Science of Learning, Commission on

Behavioral and Social Sciences and Education, National Research Council. Washington, D.C.: National Academy Press.

Borg, E. (2003). Key concepts in ELT Discourse Community. ELT Journal, 57(4), 398, Oxford University Press.

Cer, E. (2019). The instruction of writing strategies: The effect of the metacognitive strategy on the writing skills of pupils in secondary education. Sage Open Journal, 9 (2). 3-5, Sage Publications.

Chris, M., \& Jessie, L. (2017). Critical Transitions: Writing and the Question of Transfer. CSU Open press, ( $1^{\text {st }}$ ed. $), 215-246$.

Crystal, D. (1992). An encyclopedic dictionary of language and languages. Cambridge, MA: Blackwell.

Demo, D. (2001). Discourse analysis for language teachers. ERIC Digest. Eric Clearninghouse on Languages and Linguistics. Washington, DC: Center for Applied Linguistics.

Department of Education. (2019). English Language Learners (ELL) In the Mainstream, Available at https://www.state.nj.us/education/bilingual/ell_mainstream/part_four/calla.html.

Durham, P., \& Raymond, R. D. (2016). Building cognitive reading fluency through "tagging" for metacognition. Texas Journal of Literacy Education, 4(1), 46-56.

Eubanks, P. (2011). Metaphor Writing-Figurative Thought in the Discourse of Written Communication, 1, 104-153, Cambridge University Press. 
Agili, \& Prabhashini

Fenghua Lv, (2010). A study of metacognitive-strategies-based writing instruction for vocational college students. CCNET Journal, 3(3), 136-144.

Flower. L. (1994). The Construction of Negotiated Theory of Meaning-A Social Cognitive Theory of Writing, 4, 4-14. Southern Illinois University Press.

Hadley, A.O. \& Reiken, E. (1993) Teaching language in context. Florence, KY: Heinle \& Heinle Publishers.

Hales, P. (2017). Your writing, not my writing: Discourse analysis of student talk about writing. Cogent Education, 4. Taylor \& Francis Online.

Halliday, M. (1993), Towards a Language-Based Theory of Learning, Journal of Linguistics and Education 5, 93-116, University of Sydney and Macquarie University.

Harris, A. (2009). Distributed Leadership Different Perspectives-Studies in Educational Leadership-7, Springer Science+ Business Media B.V.

Hyland, K. (2004). Disciplinary Discourses-Social Interactions in Academic Writing. 1, 63. The University of Michigan Press

Kimberly, D. T., (2012). Promoting Student Metacognition. CBE Life Sciences Education, 11 (2), 113-120.

Kumaravadivelu, B. (2003). Beyond methods: Macrostrategies for language Teaching. New Haven: Yale University Press.

Larson, Bruce E. (1997). Teachers' Conceptions of Discussion as Method and Outcome. Paper presented at the Annual Meeting of the American Educational Research Association, Chicago.

Eric 4. ED:407692.

Lightbown, P., \& Spada, N. (2013). How languages are learned (4th ed.). New York: Oxford University Press.

Luan, N., \& Sappathy, S. (2011). L2 vocabulary acquisition: The impact of negotiated interaction. GEMA Online Journal of Language Studies, 11(2), 5-20. DOI: https://ejournal.ukm.my/gema/article/view/53

Negari, G. M. (2011). A study on strategy instruction and EFL learners' writing skill. International Journal of English Linguistics, 1(2), 299.

Nowacek, R. (2011). Agents of integration: Understanding transfer as a rhetorical act. Carbondale, IL: Southern Illinois University Press.

Nunan, D. (1991). Language Teaching Methodology 192. New York: Prentice Hall.

O'Malley, J. M. \& Chamot, A. U. (1990). Learning strategies in second language acquisition. Cambridge University Press, Cambridge, UK.

Osborn, J. (2015). Community Colleges and First Generation Students-Academic Discourse in the Writing Classroom, 1, 77. Palgrave McMillan, USA.

Piaget, J. (1952). When Thinking Begins. New York: International University Press.

Portanova, J. Rifenburg, M. \& Roen, D. (2017). Edited book Contemporary Perspectives on Cognition and Writing, ( $1^{\text {st }}$ ed.) 211-230. University Press of Colorado.

Schiffrin, D., Tannen, D. \& Heidi E. (2001). Edited book: The Handbook of Discourse Analysis. 707-724. Blackwell publishers Ltd. UK.

Scott, M. \& Levy, G. (2013). Metacognition: Examining the components of a fuzzy concept. Educational Research eJournal [en línea]. 2, (2). 120-131. University of Alicante. Education Faculty.

Sidney, I., \& Christian, R. (2002). Natural Discourse-Toward Ecocomposition. 1, 6. State University of New York Press.

Tannen, D., Hamilton, H. E. (Eds.), \& Schiffrin, D. (2015). The handbook of discourse 
Arab World English Journal (AWEJ) Volume 12. Number 3. September 2021

analysis. Oxford: Blackwell Publishers.

Wells, G. (1996). Discourse as tool in the activity of learning and teaching. Annual Meeting of the American Educational Research Association, New Orleans, Eric 74-101. ED:371619.

Xin, L., Luzheng, L., \& Biru, S. (2011). EFL (English as a Foreign Language) classroom discourse analysis of a vocational college and some reflections, US-China Education Review B, 6, 752-755. 